\title{
DYNAMICAL BEHAVIOUR OF THE ICE SHEET ON MIZUHO PLATEAU, EAST ANTARCTICA \\ (Abstract)
}

\author{
by
}

Fumihiko Nishio,

(National Institute of Polar Research, Kaga 1-9-10, Itabashi-ku, Tokyo 173, Japan)

Shinji Mae,

(Department of Applied Physics, Faculty of Engineering, Hokkaido University, Sapporo 060, Japan)

Hirokazu Ohmae,

(Institute of Low Temperature Science, Hokkaido University, Kita-19, Nishi-8, Kita-ku,

Sapporo 060, Japan)

Masayoshi Nakawo,

(Nagaoka Institute of Snow and Ice Studies, National Research Center for Disaster Prevention, Science and Technology Agency, Suyoshi, Nagaoka, Niigata 940, Japan)

Shuhei Takahashi,

(Kitami Institute of Technology, Kitami 090, Japan)

and

Kunio Kawata

(Faculty of Science, Toyama University, Toyama 930, Japan)

The Japanese Antarctic Research Expedition (JARE) has continued glaciological work in the Mizuho Plateau, East Antarctica. We have already reported that the ice sheet in Mizuho Plateau, which flows into Shirase Glacier and is classified as a fast-moving outlet glacier was thinning at a rate of about $70 \mathrm{~cm} /$ year, and the profile of the basal shear stress along the central flow line was similar to that of surging glaciers.

A new 5 year glaciological programme in Mizuho Plateau and East Dronning Maud Land which started in 1981 is now being carried out, and we have obtained new results as follows:

(1) The ice sheet in the down-stream region where the ice elevation is lower than about $2400 \mathrm{~m}$ is thinning, based upon data for horizontal and vertical flow velocity, strain-rate, slope of the ice surface, accumulation rate, and densification of the snow.

(2) $\delta^{18} \mathrm{O}$ analysis of deep ice cores obtained at Mizuho Station (elevation of $2240 \mathrm{~m}$ ) and point G2 (elevation of $1730 \mathrm{~m}$ ) shows that $\delta^{18} \mathrm{O}$ increased about 2000 years ago at Mizuho Station and about 400 years ago at point G2. If we can assume that the increase in $\delta^{18} \mathrm{O}$ is caused by the ice-sheet thinning, this result means that the ice-sheet thinning propagates to an up-stream area.

(3) The result of radio echo-sounding on Mizuho Plateau suggests that the base of the ice sheet in the down-stream region is wet. Based upon three-dimensional numerical modelling, the calculated bottom temperature shows that the ice temperature at the base of the ice sheet in the glacier down-stream is higher than the melting point and that the ice base is also wet. These results support the result described in (1), since the basal sliding due to a wet base causes ice-sheet thinning as suggested by our previous studies.

Summarizing these results, a possible explanation of ice-sheet variation on Mizuho Plateau is as follows: the thinning of the ice sheet caused by the basal sliding due to melting of the ice base began at Shirase Glacier and has been expanding to an up-stream area to reach the present state. A simple calculation, using flow velocities, shows that the thinning began at Shirase Glacier about 1500-2000 years ago. 